\title{
A two-step strategy for identification of plasma protein biomarkers for endometrial and ovarian cancer
}

\author{
Stefan Enroth ${ }^{1 \dagger}$, Malin Berggrund ${ }^{1 \dagger}$, Maria Lycke ${ }^{4}$, Martin Lundberg ${ }^{2}$, Erika Assarsson ${ }^{2}$, Matts Olovsson ${ }^{3}$,
} Karin Stålberg ${ }^{3}$, Karin Sundfeldt ${ }^{4 \dagger}$ and Ulf Gyllensten ${ }^{1 *+}$ (1)

\begin{abstract}
Background: Over 500,000 women worldwide are diagnosed with ovarian or endometrial cancer each year. We have used a two-step strategy to identify plasma proteins that could be used to improve the diagnosis of women with an indication of gynecologic tumor and in population screening.

Methods: In the discovery step we screened 441 proteins in plasma using the proximity extension assay (PEA) and five Olink Multiplex assays (CVD II, CVD III, INF I, ONC II, NEU I) in women with ovarian cancer ( $n=106)$, endometrial cancer $(n=74)$, benign ovarian tumors $(n=150)$ and healthy population controls $(n=399)$. Based on the discovery analyses a set of 27 proteins were selected and two focused multiplex PEA assays were developed. In a replication step the focused assays were used to study an independent set of cases with ovarian cancer $(n=280)$, endometrial cancer $(n=228)$, women with benign ovarian tumors $(n=76)$ and healthy controls $(n=57)$.

Results: In the discovery step, 27 proteins that showed an association to cancer status were identified. In the replication analyses, the focused assays distinguished benign tumors from ovarian cancer stage III-IV with a sensitivity of 0.88 and specificity of 0.92 (AUC $=0.92$ ). The assays had a significantly higher AUC for distinguishing benign tumors from late stage ovarian cancer than using CA125 and HE4 $(p=9.56 \mathrm{e}-22)$. Also, population controls could be distinguished from ovarian cancer stage III-IV with a sensitivity of 0.85 and a specificity of 0.92 (AUC $=0.89$ ).

Conclusion: The PEA assays represent useful tools for identification of new biomarkers for gynecologic cancers. The selected protein assays could be used to distinguish benign tumors from ovarian and endometrial cancer in women diagnosed with an unknown suspicious pelvic mass. The panels could also be used in population screening, for identification of women in need of specialized gynecologic transvaginal ultrasound examination.
\end{abstract}

Funding: The Swedish Cancer Foundation, Vinnova (SWELIFE), The Foundation for Strategic Research (SSF), Assar Gabrielsson Foundation.

Keywords: Ovarian cancer, Endometrial cancer, Proximity extension assay (PEA), Sensitivity, Specificity, Diagnostics

\footnotetext{
*Correspondence: ulf.gyllensten@igp.uu.se

${ }^{\dagger}$ Stefan Enroth, Malin Berggrund, Karin Sundfeldt and Ulf Gyllensten contributed equally to the study

1 Department of Immunology, Genetics, and Pathology, Biomedical Center, Science for Life Laboratory (SciLifeLab) Uppsala, Uppsala University, Box 815, 75108 Uppsala, Sweden

Full list of author information is available at the end of the article
} 


\section{Introduction}

In 2012 more than 500,000 women worldwide were diagnosed with epithelial ovarian cancer (OC) or endometrial cancer (EC) [1]. OC is the most lethal gynecologic malignancy, with 238,719 cases reported worldwide in 2012, corresponding to $3.4 \%$ of all cancer [1].

$\mathrm{OC}$ is an heterogenous disease with at least five subtypes. The biomarker CA125 can detect the most common late stage high-grade serous cancer, but lack diagnostic power for early stage and the less common ovarian adenocarcinomas, especially mucinous cancer. Also, CA125 often result in false positive results in inflammatory diseases such as endometriosis and is not regarded appropriate for fertile women, i.e. those aged 50 or below. The risk of ovarian malignancy algorithm (ROMA) is based on CA125, HE4 and menopausal status to assign women with adnexal ovarian mass into high-risk and low-risk groups. Cut-off for ROMA was estimated at a set specificity of 0.75 and has a sensitivity of 0.94 [2]. In the hands of specialists, transvaginal ultrasound (TVU) assessment can out-perform ROMA, but these specialized units are very scarce, while a serum test can be easily performed. The multivariate index assay Overa ${ }^{\circledR}$, based on five plasma proteins, can distinguish between benign tumors and $\mathrm{OC}$ with a sensitivity of 0.69 and specificity of 0.91 [3]. Additional plasma biomarkers have been described but not yet clinically evaluated [4,5]. The Risk of Ovarian Cancer Algorithm (ROCA) estimates the changes in annual CA125 measurements to identify women with high-risk scores in a screening population and refer these to specialized units for TVU examination. Use of ROCA followed by TVU has been shown to result in an increase in the number of women with OCs detected than using of a fixed cutoff for CA125, with half of these women detected by ROCA prior to CA125> 35 and the other half at the same time as CA125> 35 [6]. The United Kingdom Collaborative Trial of Ovarian Cancer Screening (UKCTOCS) has reported a reduction in ovarian cancer deaths, excluding prevalent cases, using annual screening using ROCA followed by TVU for ROCA positive subjects [7].

$\mathrm{EC}$ is the most frequent gynecologic malignancy in the developed world and in 2012 affected 319,605 women, corresponding to $7.1 \%$ of all cancer [1]. EC is diagnosed in early stage and have high 5-year survival due to early typical symptoms, such as post-menopause bleedings. Women with EC go through hysterectomy, bilateral salpingoophorectomy and after risk stratification, pelvic lymph node resection. Imaging techniques like CT, MRI and PET have shown variable performance in predicting the depth of EC, myometrial growth, cervical invasion and lymph node metastases [8]. The histopathology does not reliably reflect the underlying molecular nature of the tumors and more than $20 \%$ of tumors that were first classified as non-aggressive later develop into metastatic cancer [9]. Candidate plasma protein biomarkers have been described for EC, but in clinical practice preoperative biomarkers are lacking to stratify EC patients for lymph node resection, and to high-risk and low-risk groups for recurrence $[10,11]$.

For OC there is a strong need to identify proteins for differential diagnosis of suspicious ovarian tumors, early stage detection and sub-type specific diagnosis as complements to HE4 and CA125, in order to refer women to specific imaging techniques, reduce overtreatment and identify women with ovarian malignancy. For EC, biomarkers are needed for stratification of patients to different surgical interventions. In this study, we have used the proximity extension assay (PEA) to identify plasma proteins with a higher sensitivity and specificity that could be used to address the diagnostic needs for the two cancer types.

\section{Materials and methods Clinical material and ethics approval}

The plasma samples of women with ovarian and endometrial tumors were from the UCAN collection at Uppsala Biobank, Uppsala University (UU), and the Gynecology tumor biobank at Sahlgrenska University Hospital (SU) (Table 1). All tumors were examined by a pathologist specialized in gynecologic cancers for histology, grade and stage according to International Federation of Gynecology and Obstetrics (FIGO) standards. Plasma samples from women with an indication of adnexal ovarian mass based on TVU and that received a diagnosis of benign conditions, including simple cysts (inclusion cysts, rete ovarii cysts, mesonephric cysts), follicle and corpora luteum cysts, endometriosis, teratoma and benign adenoma, were included as benign tumors. The plasma samples from healthy population controls were from women participating in The Northern Sweden Population Health Study (NSPHS) and from controls in the UCAN collection (Table 1). All plasma samples were frozen and stored at $-70{ }^{\circ} \mathrm{C}$ until used in the study.

\section{Plasma protein measurements}

The abundance of 441 unique protein in plasma were analyzed using the Olink Multiplex assays CVD II, CVD III, INF I, ONC II and NEU I (http://www.olink.com) and quantified by real-time PCR using the Fluidigm BioMark $^{\mathrm{TM}}$ HD real-time PCR platform as described earlier [12]. Briefly, for each protein a unique pair of oligonucleotide-labeled antibody probes bind to the targeted protein, and if the two probes are in close proximity a PCR target sequence is formed by a proximity-dependent DNA polymerization event and the resulting sequence 
Table 1 Baseline information for women included in the discovery and replication steps

\begin{tabular}{|c|c|c|c|c|c|c|c|c|c|}
\hline & \multicolumn{4}{|l|}{ Discovery } & \multicolumn{5}{|c|}{ Replication } \\
\hline & $\begin{array}{l}\text { Benign } \\
\text { tumors } \\
\text { cohort I }\end{array}$ & $\begin{array}{l}\text { Ovarian } \\
\text { cancer } \\
\text { cohort I }\end{array}$ & $\begin{array}{l}\text { Endometrial } \\
\text { cancer cohort I }\end{array}$ & $\begin{array}{l}\text { Population } \\
\text { controls I }\end{array}$ & $\begin{array}{l}\text { Benign } \\
\text { tumors } \\
\text { cohort II }\end{array}$ & $\begin{array}{l}\text { Ovarian } \\
\text { cancer } \\
\text { cohort II }\end{array}$ & $\begin{array}{l}\text { Ovarian } \\
\text { cancer } \\
\text { cohort III }\end{array}$ & $\begin{array}{l}\text { Endometrial } \\
\text { cancer cohort }\end{array}$ & $\begin{array}{l}\text { Population } \\
\text { controls II }\end{array}$ \\
\hline $\begin{array}{c}\text { Number of } \\
\text { women }\end{array}$ & $150(\mathrm{SAL} 1)$ & 106 (SAL1) & 74 (SU1) & 399 (NSPHS) & 76 (SU2) & 160 (SU2) & 120 (UU) & 228 (UU) & 57 (UU) \\
\hline \multicolumn{10}{|l|}{ Age } \\
\hline Mean & 59.8 & 61.2 & 59.84 & 49.3 & 60.8 & 61.8 & 60.9 & 66.8 & 57.3 \\
\hline Median & 60 & 60 & 60 & 49 & 63 & 63 & 62 & 68 & 58 \\
\hline Range & $16-88$ & $28-88$ & $29-86$ & 14-94 & $22-88$ & 19-87 & $21-86$ & 29-90 & $18-86$ \\
\hline $\mathrm{SD}$ & 15.8 & 12.9 & 10.75974 & 20.3 & 14.5 & 11.9 & 12.9 & 10.5 & 14.2 \\
\hline $\begin{array}{l}\text { P-value } \\
\text { versus } \\
\text { benign }\end{array}$ & NA & 0.870 & 0.003665 & $2.22 \mathrm{E}-08$ & NA & 0.868 & 0.937 & 0.001 & 0.163 \\
\hline $\begin{array}{l}\text { Ethnicity } \\
\text { Stage }\end{array}$ & Caucasian & Caucasian & Caucasian & Caucasian & Caucasian & Caucasian & Caucasian & Caucasian & Caucasian \\
\hline I (I/IA/IB) & & 46 & $50(0 / 41 / 9)$ & & & 35 & 10 & $109(3 / 83 / 23)$ & \\
\hline$\|(\|/\| A / \| B)$ & & 8 & $8(8 / 0 / 0)$ & & & 9 & 3 & $13(12 / 0 / 1)$ & \\
\hline $\begin{array}{l}\text { III (III/IIIA/IIIB/ } \\
\text { IIIC/IIIC1/ } \\
\text { IIIC2) }\end{array}$ & & 47 & $10(0 / 2 / 2 / 0 / 2 / 4)$ & & & 96 & 40 & $22(1 / 4 / 4 / 5 / 1 / 7)$ & \\
\hline $\begin{array}{l}\text { IV (IV/IVA/ } \\
\text { IVB) }\end{array}$ & & 5 & $6(2 / 0 / 4)$ & & & 19 & 24 & $11(5 / 0 / 6)$ & \\
\hline $\begin{array}{c}\text { Classification } \\
\text { unvailable }\end{array}$ & & & & & & 1 & 43 & 73 & \\
\hline
\end{tabular}

is subsequently detected and quantified using standard real-time PCR. Data is then normalized and transformed using internal extension controls and inter-plate controls, to adjust for intra- and inter-run variation as described earlier [12]. The final assay read-out is given in Normalized Protein eXpression (NPX), which is an arbitrary unit on $\log 2$-scale where a high value corresponds to a higher protein expression. Each PEA measurement has a lower detection limit (LOD) calculated based on negative controls that are included in each run, and measurements below LOD were removed from further analysis. All assay characteristics including detection limits and measurements of assay performance and validations are available from the manufacturers webpage (http://www.olink .com). The analyses were based on $1 \mu \mathrm{L}$ of plasma for each panel of 92 assays. To avoid batch effects, samples from the different disease entities and cohorts, including benign tumors, were randomized across assay plates. Each plate included internal controls, as described previously used to adjust for technical variation and/or sample irregularities.

\section{Development of focused multiplex PEA panels}

The focused PEA assays were designed to be compatible with the Fluidigm $192 \times 24$ Integrated Fluidic Circuit (IFC) which can measure up to 24 assays on 192 samples simultaneously. Hence, 21 protein marker assays and three internal controls for run QC (Incubation Control, Extension Control and Detection control) can be analyzed per IFC. The main difference between the focused assays and the discovery assays is that the focused assays allow higher PEA probe concentration, which in turn means that higher levels of antigen can be measured without reaching the hook in the measuring range (i.e. too much antigen will decrease signals in a homogenous immunoassay format). This modification allowed inclusion of PEA assays from the CVD III panel, where samples are normally diluted 1:100 before analysis, into the focused assays used to analyze undiluted samples, making the differences in protein concentration to be measured more than 7 logs.

\section{Statistical methods}

All calculations were carried out in $\mathrm{R}$ version 3.2.3 ( $\mathrm{R}$ core team) [13]. Individual protein levels were also normalized by plate and sampling round using the MDimNormn-package [14]. This was done separately for the discovery and replication cohorts.

Significance levels for comparison of protein levels between cases and controls in the discovery cohort were calculated using the two-sided rank-based Spearman test (Wilcoxon). From the entire discovery-cohort, 
the top-ranking proteins for each of the two cancers was identified based on the $p$ value in the comparison of benign tumors to cancer samples. 15 proteins were selected for association with OC and 16 with EC out of which 4 overlapped. Lasso and Elastic-Net Regularized Generalized Linear Models ('glmnet' package in R) was used to fit multivariate models for each cancer using the selected proteins. These models were then evaluated based on the best point and their specificity at a fixed sensitivity of 0.95 . This was repeated for each of the tumor/control combination investigated.

A few proteins overlapped between the two cancers, and a total of 27 proteins were selected to be characterized in the replication cohort using focused PEA-panels.

Model performance was evaluated by randomly splitting the observations in the replication cohort into a training set (75\%) and a test set (25\%). A model was then built using the training set and with the same proteins as selected from the discovery-cohort. The multivariate models were retrained in the replication cohorts using the ' $I m$ ' function in $R$. The reason for re-building the model in the replication data set is that the scaling of the NPX-values can differ between the multiplex PEA panels. This model was then used to predict the response variable in the test set. The random-split into training and test set will often result in different performance due to the limited sample-size. To accommodate for this, a cross-validation schema was applied and the process was repeated 100 times and model prediction errors on the training and test set were recorded. Sensitivity and specificity from the replication were reported as mean $\pm 1 \mathrm{SD}$ of the 100 runs.

\section{Results}

\section{Discovery step analyses}

The protein biomarker panels were identified using a two-step study design (Fig. 1). First, the levels of 441 individual proteins was measured in pretreatment plasma collected at time of diagnosis from women with $\mathrm{OC}$ or EC and compared to benign tumors and population controls (Table 1). No difference was found in the mean age of women with benign tumors and OC (stage I-IV) or between healthy controls and women with OC (Table 1). $\mathrm{EC}$ is diagnosed at a higher age than $\mathrm{OC}$, which is reflected in the age difference seen between women with $\mathrm{EC}$ and those with benign tumors (Table 1).

The distribution of differences in protein abundance (NPX-values) between women with OC or EC and benign tumors is shown for all proteins in Fig. 2. Proteins with a significant (Bonferroni-corrected significance threshold) difference in NPX values between benign tumors and OC (Fig. 2a-c) and between OC and EC (Fig. 2d) are labelled by name. The clinically used biomarker CA125 showed

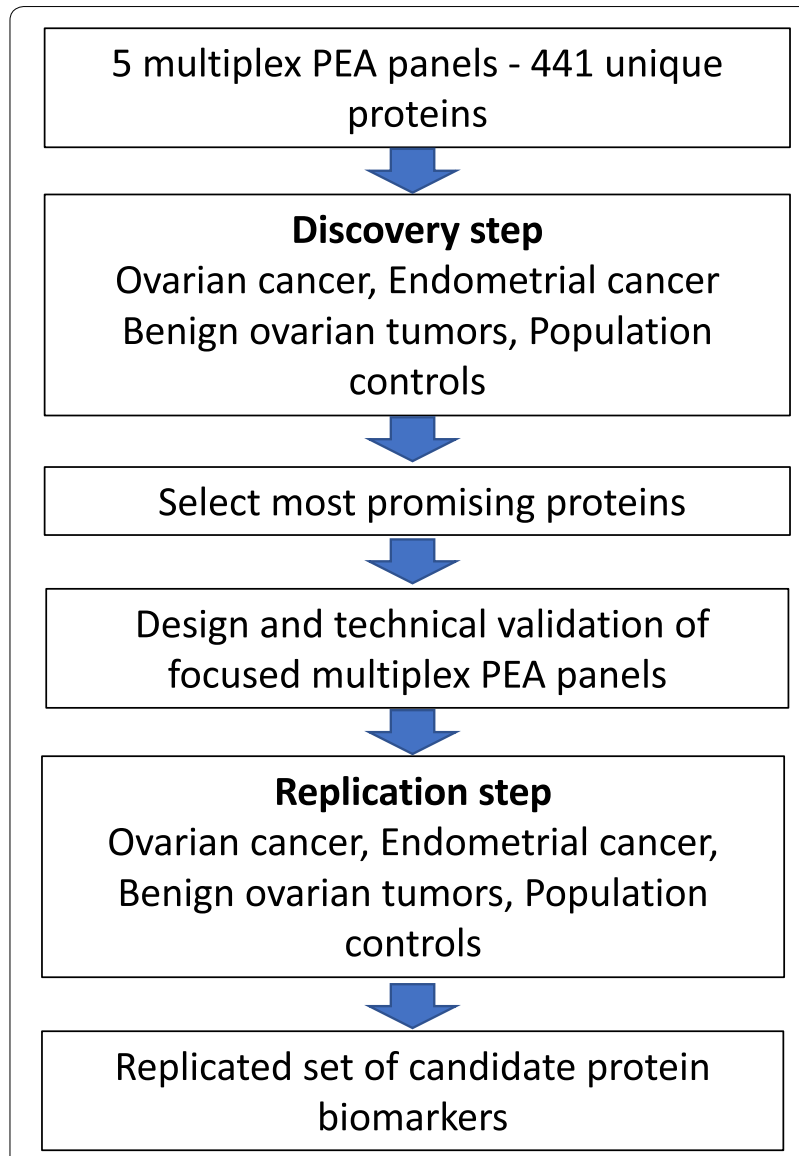

Fig. 1 The study design for identification of protein biomarkers using PEA

the largest differences in NPX value between OC cases and benign tumors. Nominal $p$-values for the comparisons of $\mathrm{OC}$ or EC with benign tumors and population controls are given for each protein in Additional file 1: Table 1.

Employing the approach described in the methods section, 27 of the 441 proteins in the discovery analysis were selected for further evaluation. Of these, 15 proteins (PRSS8, MK, WFDC2 (HE4), IL-10, SOD2, PARP1, hK11, PVRL4, MUC-16 (CA125), FR-alpha, CDH3, NTRK3, IL-8, IL-17C, EN-RAGE) were selected from the comparison between OC stage I-IV and benign tumors (Table 2). Further, 16 proteins (PRSS8, MK, WFDC2 (HE4), IL-10, ADM, IDUA, MMP-7, FABP4, PCSK9, ST2, CTSZ, CCL16, Dkk-4, VEGF-A, IL-6, HGF) were selected from the comparison of EC with benign tumors (Table 3). Four of the proteins (PRSS8, MK, WFDC2, IL-10) were selected for both OC and EC.

At the highest AUC (best point analysis) the 15-protein selected for $\mathrm{OC}$ could distinguish women with benign tumors from those with OC stage I-IV with a 

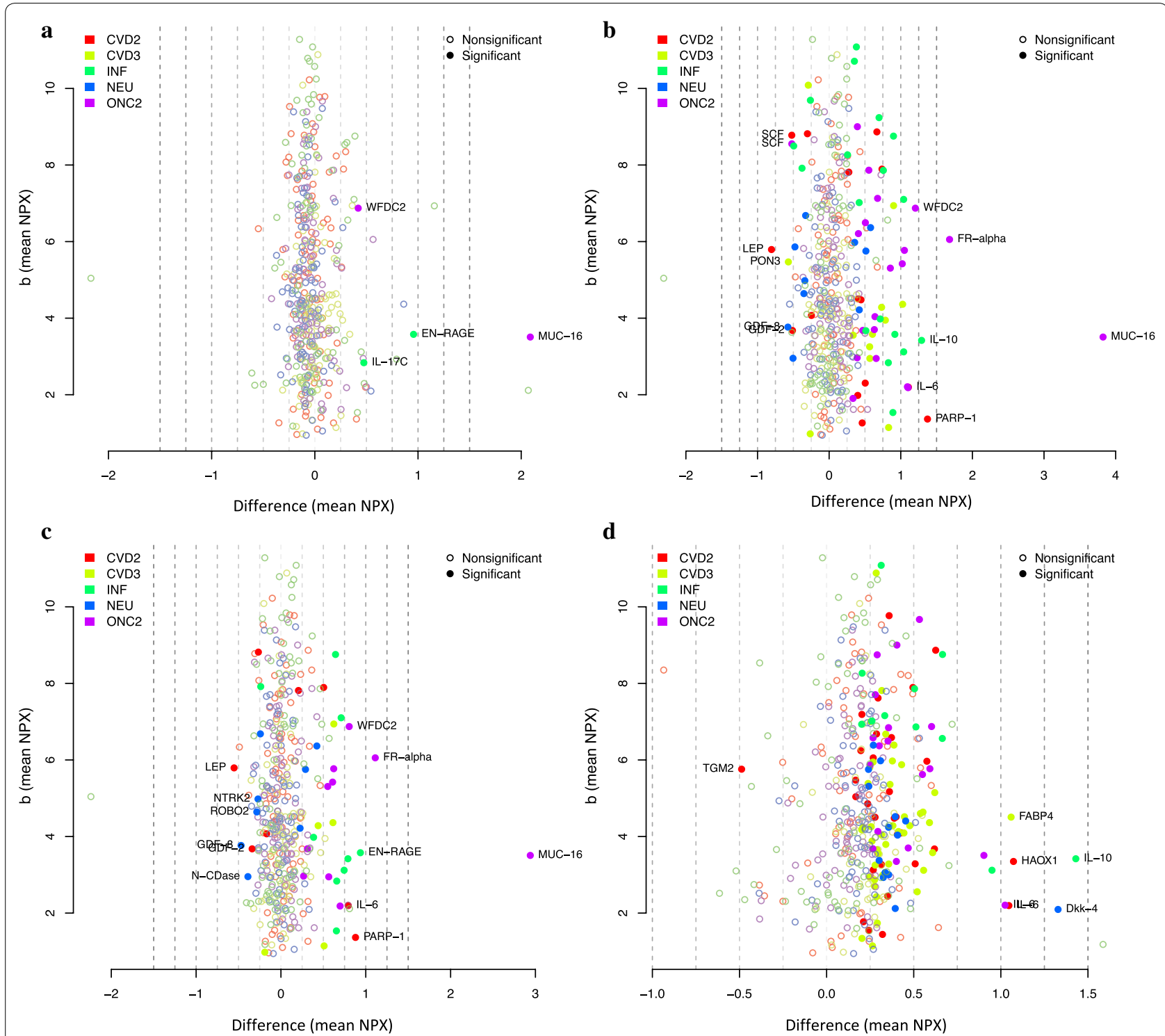

d

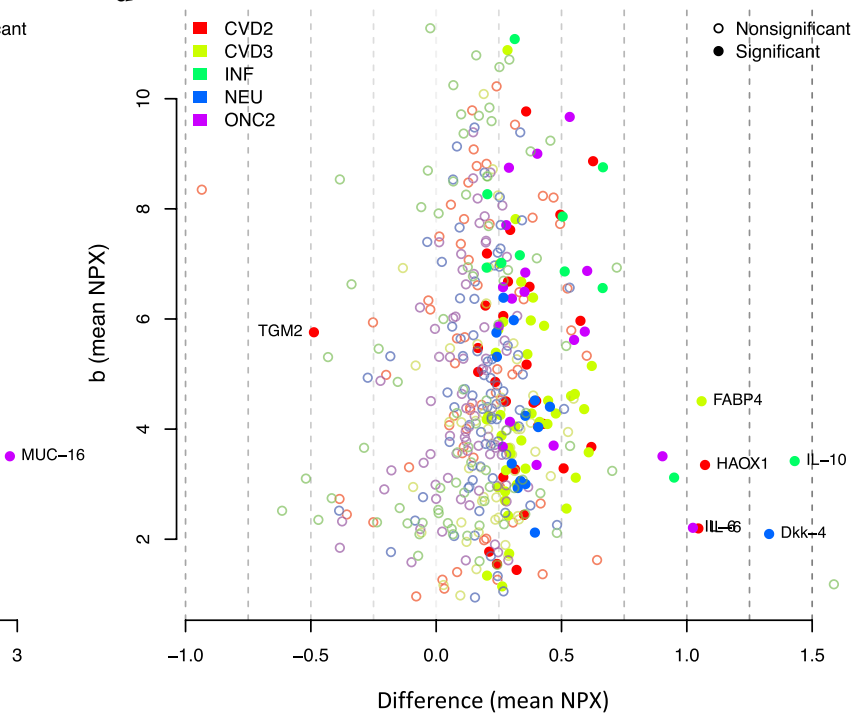

Fig. 2 Distribution of differences in NPX values in the discovery step between benign tumors and OC (a-c) and between OC and EC (d). Only protein labels for the significant differences are shown

sensitivity $=0.79$ and specificity $=0.85 \quad(\mathrm{AUC}=0.86)$, from OC stage I-II with a sensitivity $=0.68$ and specificity $=0.73(\mathrm{AUC}=0.72)$ and from OC stage III-IV with a sensitivity $=0.93$ and specificity $=0.93($ AUC $=0.95)$ (Table 4, Fig. 3). At a minimum sensitivity of 0.95 , as a cutoff value for the biomarker panel to be used as a preoperative diagnostic test, the specificity to distinguish between benign ovarian tumors and OC stage III-IV was 0.54 (Table 4).

The 15-protein panel was also able to distinguish population controls from OC stage I-IV with a sensitivity $=0.75$ and specificity $=0.87 \quad(\mathrm{AUC}=0.86)$, from $\mathrm{OC}$ stage I-II with a sensitivity $=0.70$ and specificity $=0.75$
$(\mathrm{AUC}=0.74)$ and from OC stage III-IV with a sensitivity $=0.94$ and specificity $=0.96($ AUC $=0.97) \quad($ Table 4$)$. At a specificity of 0.96 , as a cutoff value for the biomarker panel to be useful in population screening, the sensitivity to distinguish controls from OC stage I-IV was 0.66, from OC stage I-II it was 0.43 and from OC stage III-IV it was 0.92 (Table 4).

Since plasma samples from benign tumors and OC stage I-IV had been analyzed previously for CA125 we compared our CA125 values from PEA with those from the Architect CA125-II assay (Abbott Diagnostics, Abbott Park, IL, USA). There was a strong correlation between the two measurements $\left(R^{2}=0.87, p\right.$ 


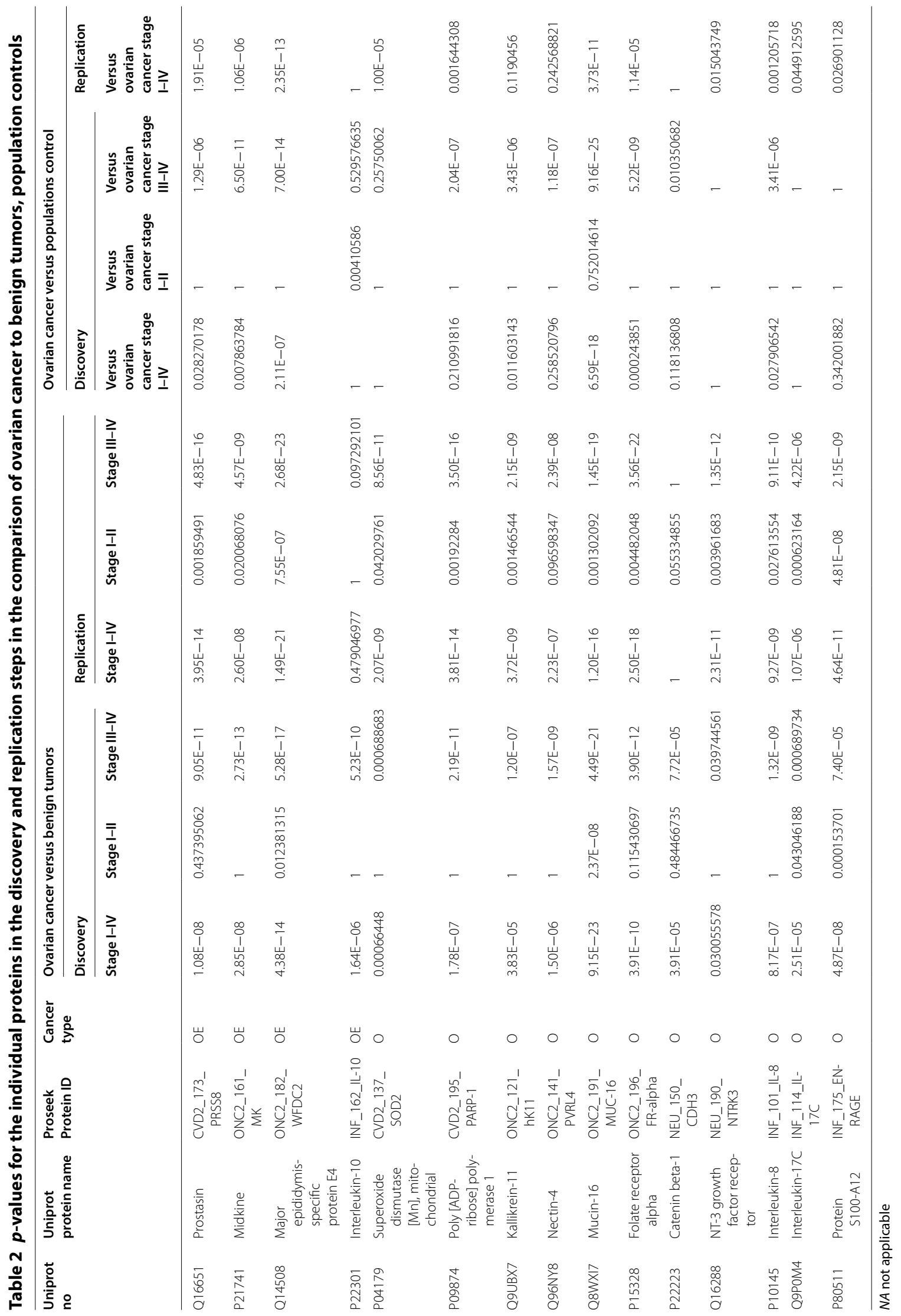


Table $3 p$-values for the individual proteins in the discovery and replication steps in the comparison of endometrial cancer to benign tumors, population controls and ovarian cancer

\begin{tabular}{|c|c|c|c|c|c|c|c|c|c|}
\hline \multirow[t]{2}{*}{ Uniprot no } & \multirow[t]{2}{*}{$\begin{array}{l}\text { Uniprot protein } \\
\text { name }\end{array}$} & \multirow[t]{2}{*}{$\begin{array}{l}\text { Proseek protein } \\
\text { ID }\end{array}$} & \multirow[t]{2}{*}{ Cancer } & \multicolumn{2}{|c|}{$\begin{array}{l}\text { Endometrial cancer } \\
\text { versus benign cysts }\end{array}$} & \multicolumn{2}{|c|}{$\begin{array}{l}\text { Endometrial cancer } \\
\text { versus ovarian cancer } \\
1-4\end{array}$} & \multicolumn{2}{|c|}{$\begin{array}{l}\text { Endometrial cancer } \\
\text { versus population } \\
\text { controls }\end{array}$} \\
\hline & & & & Discovery & Replication & Discovery & Replication & Discovery & Replication \\
\hline Q16651 & Prostasin & CVD2_173_PRSS8 & $\mathrm{OE}$ & $4.36 \mathrm{E}-09$ & $6.88 \mathrm{E}-08$ & 1 & $3.22 \mathrm{E}-07$ & 0.01381015 & 0.928202706 \\
\hline P21741 & Midkine & ONC2_161_MK & $\mathrm{OE}$ & $3.65 E-08$ & 0.119795419 & 1 & $8.20 E-09$ & 0.026477007 & 1 \\
\hline Q14508 & $\begin{array}{l}\text { Major epididymis- } \\
\text { specific protein } \\
\text { E4 (WAP four- } \\
\text { disulfide core } \\
\text { domain protein } \\
\text { 2) }\end{array}$ & $\begin{array}{l}\text { ONC2_182 } \\
\text { WFDC2 }\end{array}$ & $\mathrm{OE}$ & $6.28 \mathrm{E}-09$ & $1.71 \mathrm{E}-10$ & 1 & $2.83 E-12$ & 0.290677608 & 0.00019993 \\
\hline P22301 & Interleukin 10 & INF_162_IL-10 & $\mathrm{OE}$ & $4.23 E-12$ & 1 & 1 & 1 & 0.065101325 & 1 \\
\hline P35318 & Adenomedulin & CVD2_103_ADM & $E$ & $2.48 \mathrm{E}-07$ & 0.004662956 & 0.005277639 & 1 & $5.23 \mathrm{E}-05$ & 0.608471686 \\
\hline P35475 & $\begin{array}{l}\text { Al pha-L-iduroni- } \\
\text { dase }\end{array}$ & CVD2_116_IDUA & $\mathrm{E}$ & 1.05E-05 & 0.954600936 & $6.83 E-10$ & 1 & $6.52 E-08$ & 0.443914788 \\
\hline P09237 & Matrilysin & CVD2_167_MMP-7 & $E$ & $7.21 \mathrm{E}-06$ & 0.000194133 & 1 & 0.112528602 & 0.001380847 & 0.000174466 \\
\hline P15090 & $\begin{array}{l}\text { Fatty acid-binding } \\
\text { protein, adipo- } \\
\text { cyte }\end{array}$ & CVD3_129_FABP4 & $\mathrm{E}$ & $1.10 \mathrm{E}-06$ & 1 & 0.01262521 & 1 & 0.000231174 & 0.023151067 \\
\hline Q8NBP7 & $\begin{array}{l}\text { Proprotein } \\
\text { convertase } \\
\text { subtilisin/kexin } \\
\text { type } 9\end{array}$ & CVD3_161_PCSK9 & $E$ & $1.43 \mathrm{E}-05$ & 1 & $2.42 \mathrm{E}-05$ & 1 & 0.002207816 & 1 \\
\hline Q01638 & $\begin{array}{l}\text { Interleukin-1 } \\
\text { receptor-like } 1\end{array}$ & CVD3_176_ST2 & E & $1.35 \mathrm{E}-06$ & 0.010291606 & 0.023539896 & 1 & 0.000249695 & 0.242686447 \\
\hline Q9UBR2 & Cathepsin Z & CVD3_185_CTSZ & $\mathrm{E}$ & $3.20 \mathrm{E}-07$ & 1 & $3.59 \mathrm{E}-06$ & 1 & $2.28 \mathrm{E}-06$ & 1 \\
\hline 015467 & $\begin{array}{l}\text { C-C motif } \\
\text { chemokine } 16\end{array}$ & CVD3_196_CCL16 & $E$ & $2.70 \mathrm{E}-06$ & 1 & 0.48003849 & 0.006484386 & 0.005950521 & 1 \\
\hline Q9UBT3 & $\begin{array}{l}\text { Dickkopf-related } \\
\text { protein } 4\end{array}$ & NEU_187_Dkk-4 & $E$ & 2.60E-09 & 1 & $4.27 \mathrm{E}-05$ & 0.252055749 & 0.000134061 & 0.022042978 \\
\hline P15692 & $\begin{array}{l}\text { Vascular endothe- } \\
\text { lial growth } \\
\text { factor A }\end{array}$ & INF_102_VEGF-A & E & 0.00150827 & $1.88 \mathrm{E}-06$ & 1 & 4.56E-05 & 0.156267791 & 1 \\
\hline P05231 & Interleukin-6 & INF_113_IL-6 & E & 0.000735048 & $1.41 \mathrm{E}-05$ & 1 & $5.49 \mathrm{E}-06$ & 1 & 1 \\
\hline P08581 & $\begin{array}{l}\text { Hepatocyte } \\
\text { growth factor } \\
\text { receptor }\end{array}$ & INF_156_HGF & $E$ & $6.46 \mathrm{E}-05$ & $6.46 \mathrm{E}-05$ & $6.46 \mathrm{E}-05$ & $6.46 \mathrm{E}-05$ & $6.46 \mathrm{E}-05$ & 0.010198277 \\
\hline
\end{tabular}

NA not applicable

value $<6.72 \mathrm{e}-128)$, except for the highest values which were outside the linear part of the range for PEA (Fig. 4 , Additional file 2: Table 2).

For EC the 16-protein panel distinguished benign tumors from $\mathrm{EC}$ with a sensitivity $=0.77$ and specificity $=0.79(\mathrm{AUC}=0.83)$. OC stage I-IV could be distinguished from EC with a sensitivity of 0.84 and specificity of 0.88 (AUC $=0.89$ ). Finally, the EC patients could be distinguished from population controls with a sensitivity $=0.69$ and specificity $=0.78(\mathrm{AUC}=0.76)($ Table 4$)$.

\section{Replication step}

Two focused multiplex PEA assays were developed for the 27 proteins identified in the discovery step, according to the protocol described by the manufacturer [15]. There was excellent correlation between the protein estimates from the multiplex assays used in the discovery step and the focused PEA assays used in the replication step (Fig. 5). Despite absolute differences in NPX-values (as expected since the dynamic range was shifted for some assays in the custom panel) the rank of different proteins was maintained (Fig. 5). Average intra- and interassay $\mathrm{CV}$ for 17 of the proteins included in the discovery and replication assays have previously been shown to be similar to the Olink's commercial 92-plex screening panels [15]. Thus, the results of the PEA analyses used in the discovery and the replication steps were considered comparable. 


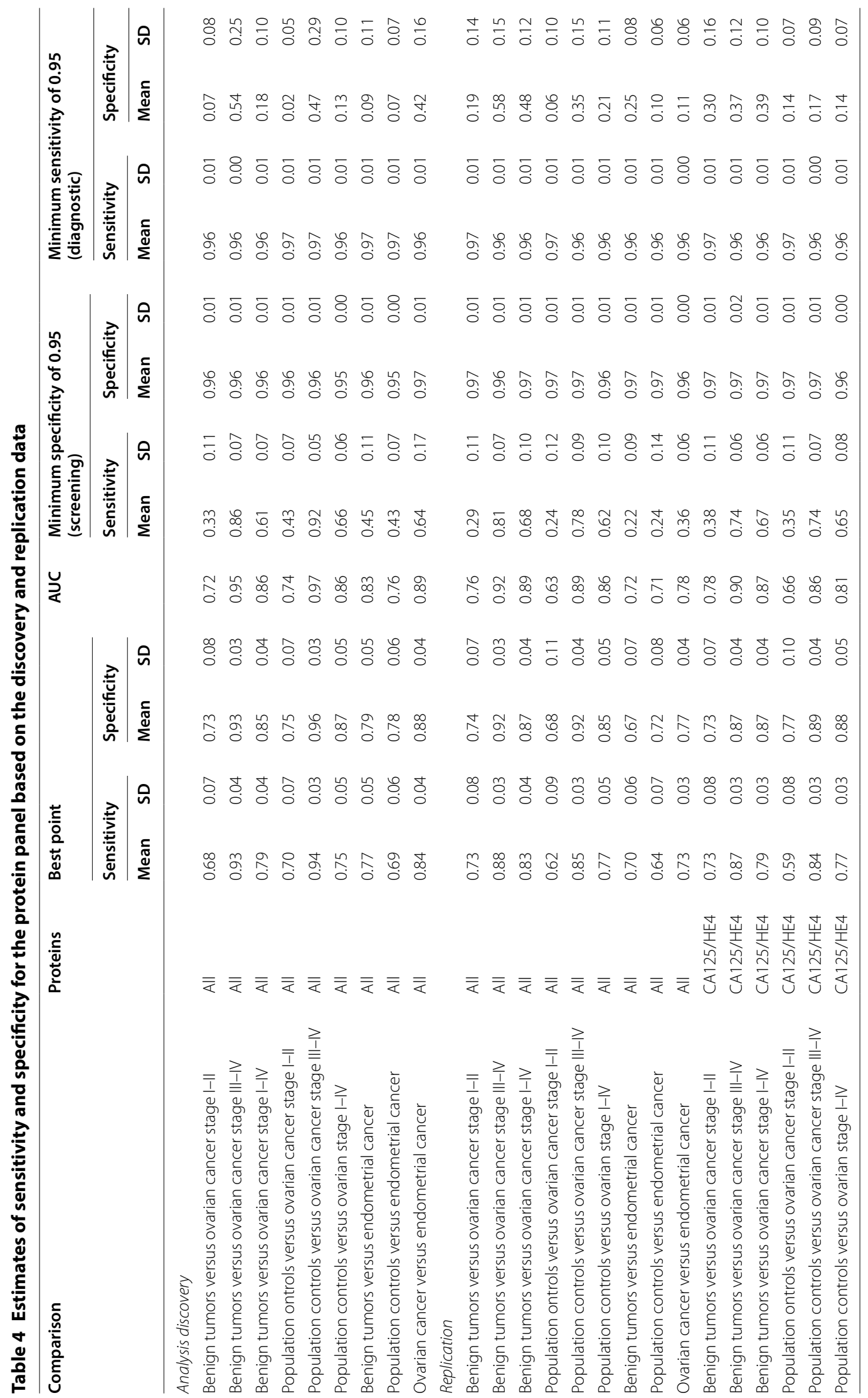



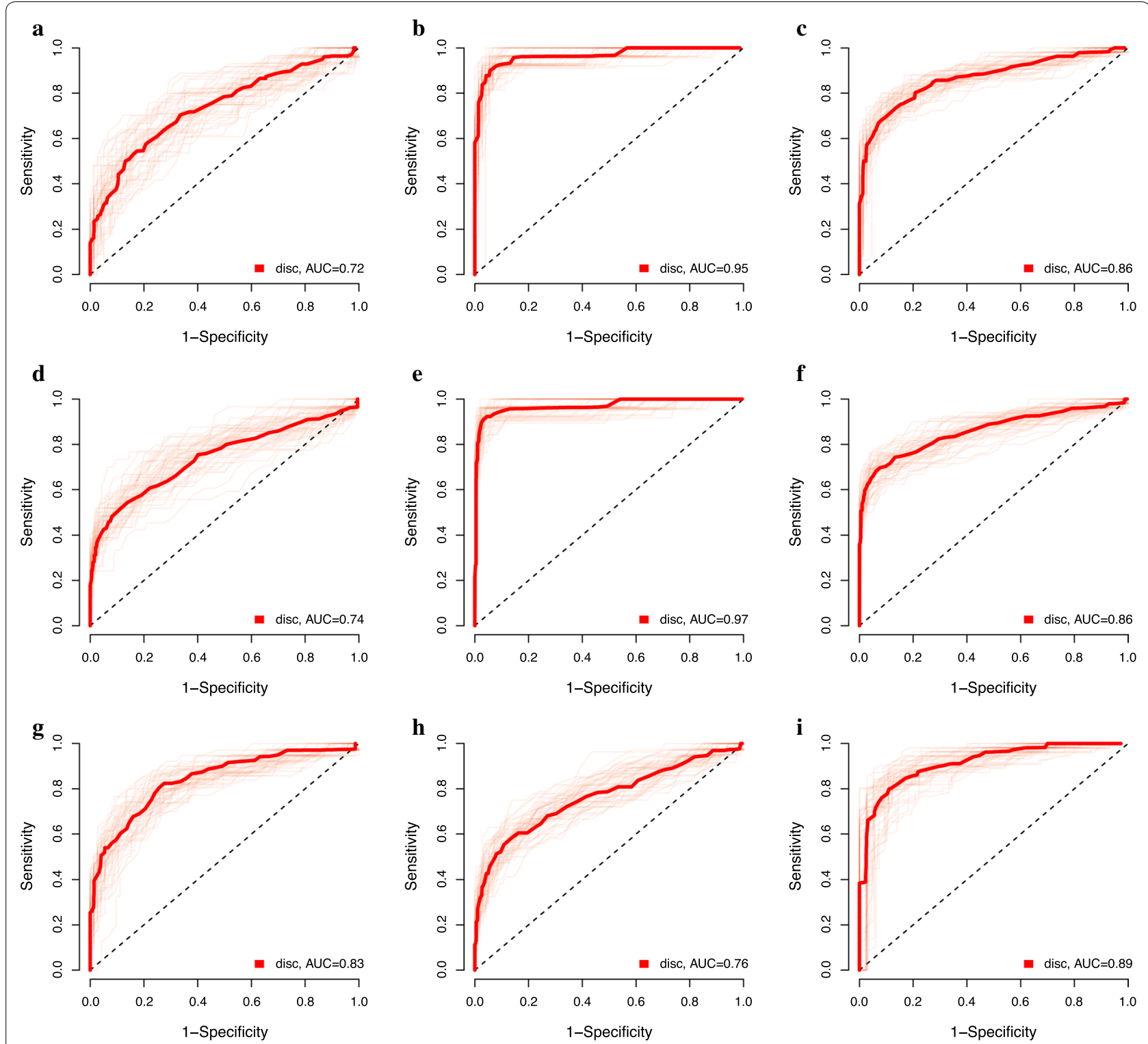

Fig. 3 Reporter operator characteristic (ROC) for combinations of proteins in the discovery step. a Benign tumors versus Ovarian cancer stage I-II. b Benign tumors versus Ovarian cancer stage III-IV. c Benign tumors versus Ovarian cancer stage I-IV. d Population controls versus Ovarian cancer stage I-II. e Population controls versus Ovarian cancer stage III-IV. f Population controls versus Ovarian cancer stage I-IV. $\mathbf{g}$ Benign tumors versus Endometrial cancer. $\mathbf{h}$ Controls versus Endometrial cancer. i Ovarian cancer stage I-IV versus endometrial cancer versus

The focused PEA panels were then used to study an independent set of plasma samples from women with either of the two cancers, benign tumors and population controls (Table 1). For OC, the association was replicated for 13 of the 15 proteins and only IL-10 and CDH3 showed no association with OC. The protein panel distinguished benign tumors from OC stage I-IV with a sensitivity $=0.83$ and specificity $=0.87 \quad(\mathrm{AUC}=0.89)$, from OC stage I-II with a sensitivity $=0.73$ and specificity $=0.74(\mathrm{AUC}=0.76)$ and from OC stage III-IV with a sensitivity $=0.88$ and specificity $=0.92 \quad(\mathrm{AUC}=0.92)$ (Table 4, Fig. 6). The protein panel selected for OC had a significantly higher AUC than using only CA125 and HE4 for distinguishing benign tumors from OC (stage IIV, $p=1.41 \mathrm{e}-13$; stage $3-4, p=9.56 \mathrm{e}-22$ ). At a sensitivity of 0.96 , the specificity to distinguish between benign ovarian tumors and OC stage I-IV was 0.48 , stage I-II it was 0.19 and stage III-IV it was 0.58 (Table 4).

The selected protein panel distinguished population controls from OC stage I-IV with a sensitivity $=0.77$ and 


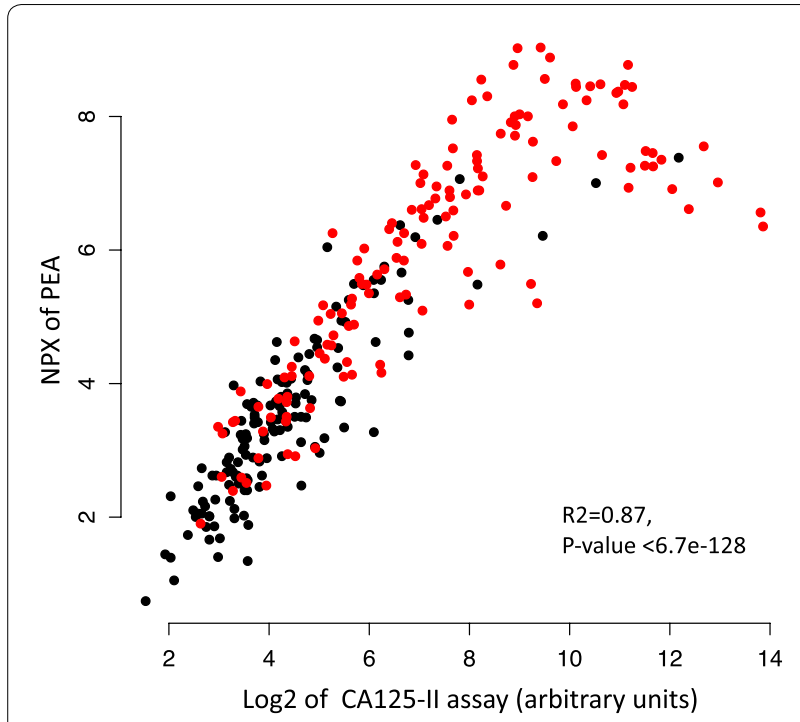

Fig. 4 Correlation between CA125 values from the multiplex PEA used in the discovery step and from clinical ELISA, for benign tumors (in black) and ovarian cancer patients (in red) specificity $=0.85(\mathrm{AUC}=0.86)$, from OC stage I-II with a sensitivity $=0.62$ and specificity $=0.68 \quad(\mathrm{AUC}=0.63)$, and from OC stage III-IV with a sensitivity $=0.85$ and specificity $=0.92 \quad($ AUC $=0.89) \quad($ Table 4 , Fig. 6). At a minimum specificity of 0.95 , the sensitivity to distinguish population controls from OC stage I-IV was 0.62 , from OC stage I-II it was 0.24 , and from OC stage III-IC it was 0.78 (Table 4 ).

In a recent study, candidate biomarkers for $\mathrm{OC}$ were identified using the Olink Multiplex ONC I v2 panel [5]. That panel is discontinued by the manufacturer and replaced by the ONC II panel used here. However, some of the proteins overlap with the panels used here, and we therefore compared the AUC values for these proteins in the two studies (Fig. 7a). There was good correlation in the comparison of benign tumors to OC stage III-IV, but the AUC values were generally higher in the study by Boylan et al. [5]. By contrast, no correlation was found in the AUC values when comparing benign tumors and OC stage I-II (Fig. 7b).
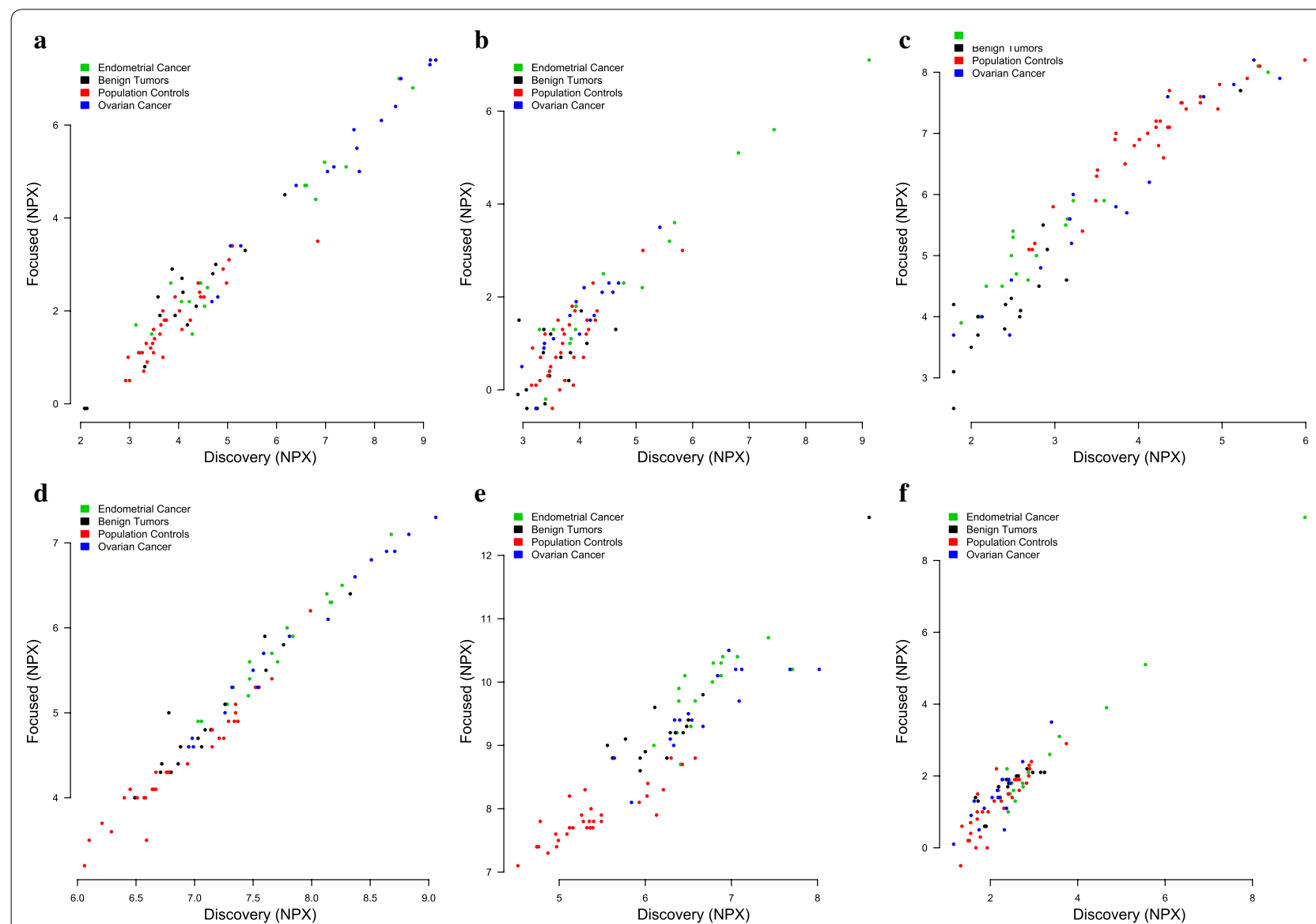

Fig. 5 Correlation in protein abundance between the 92-plex panels and the focused protein panels for the six proteins a CA125, b IL 10, c ENRAGE, d HE4, e MK, f Dkk4 

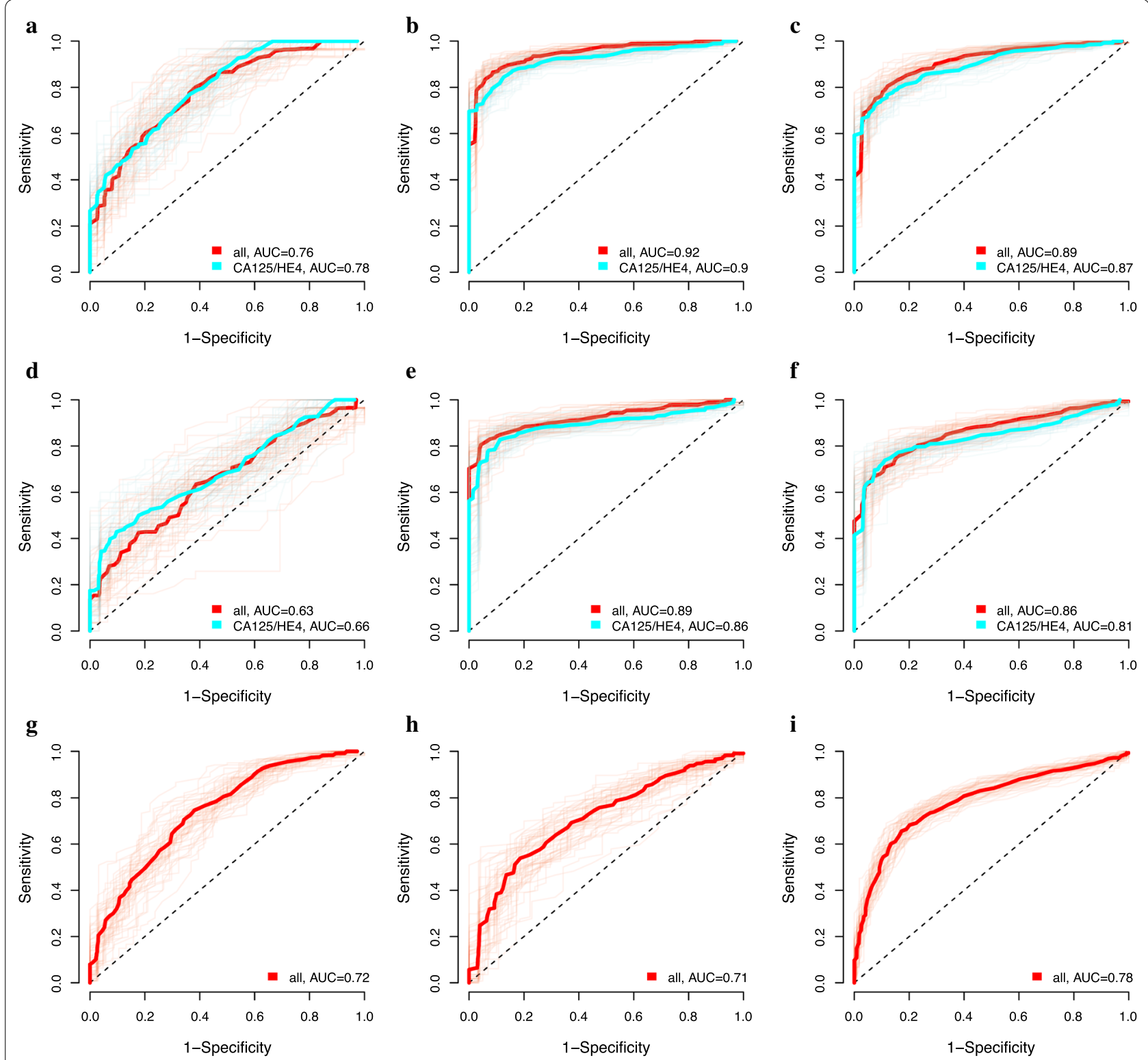

Fig. 6 Reporter operator characteristic (ROC) for combinations of proteins in replication stage. The blue line is using CA125 and HE4 only. a Benign tumors versus Ovarian cancer stage I-II. b Benign tumors versus Ovarian cancer stage III-IV. c Benign tumors versus Ovarian cancer stage I-IV. d Population controls versus Ovarian cancer stage I-II. e Population controls versus Ovarian cancer stage III-IV. f Population controls versus Ovarian cancer stage I-IV. g Benign tumors versus Endometrial cancer. $\mathbf{h}$ Controls versus Endometrial cancer. i Ovarian cancer stage I-IV versus endometrial cancer versus

Of the 16 proteins selected for EC, an association was replicated for nine (PRSS8, MK, WFDC2 (HE4), ADM, MMP-7, ST2, VEGF-A, IL-6, HGF), while seven proteins showed no association (IL-10, IDUA, FABP-4, PCSK9, CTSZ, CCL16, Dkk-4). The protein panel distinguished between benign tumors and $\mathrm{EC}$ with a sensitivity $=0.70$ and a specificity $=0.67(\mathrm{AUC}=0.72)$. Population controls could be distinguished from EC with a sensitivity $=0.64$ and specificity $=0.72(\mathrm{AUC}=0.71)$.
Of the 13 proteins that differed significantly between OC stage I-IV and EC in the discovery data, six (hK11, MUCIN-16, FR-alpha, NTRK3, EN-RAGE, HGF) showed a significant difference in the replication step (Tables 2, 3). OC stage I-IV could be distinguished from EC with a sensitivity $=0.73$ and a specificity $=0.77(\mathrm{AUC}=0.78)$. 

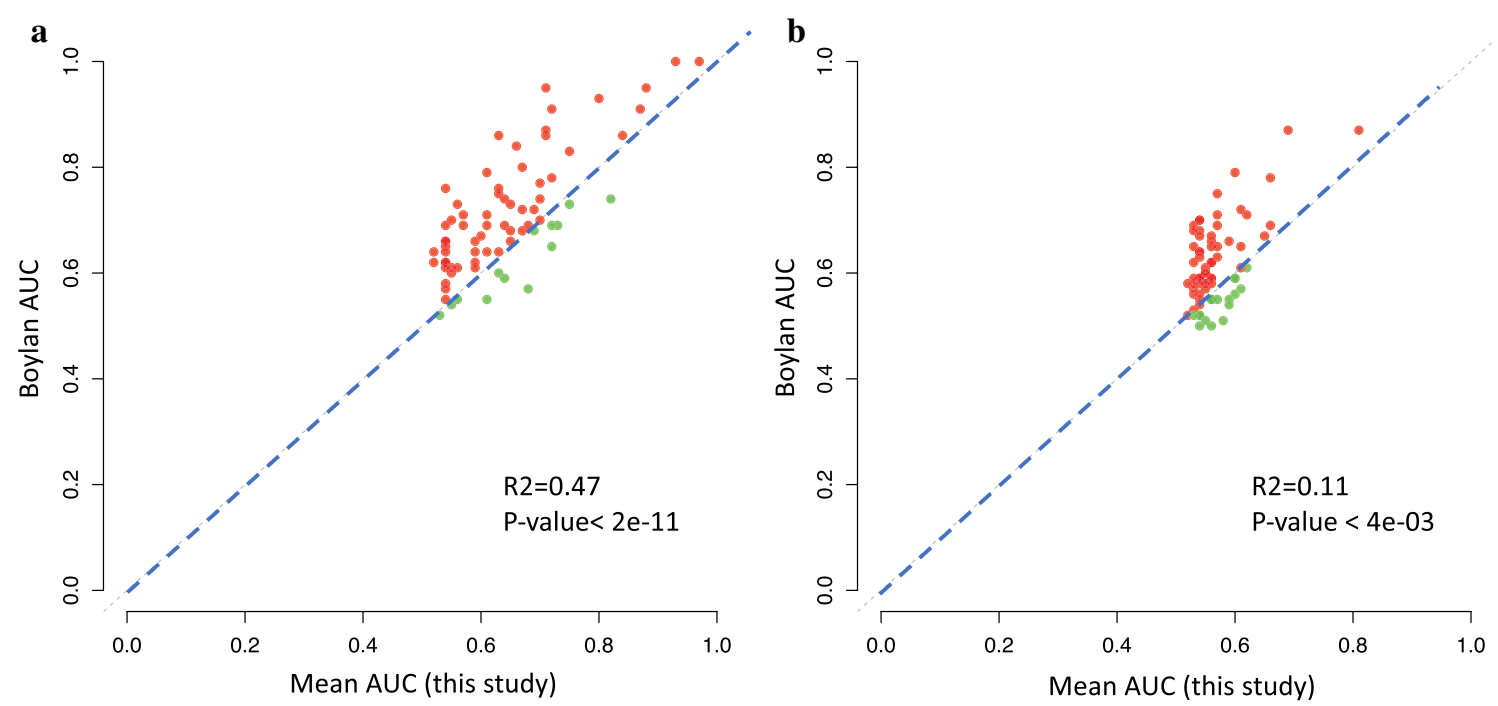

Fig. 7 Correlation between AUC values for some of the proteins overlapping between our study and that by Boylan et al. [5] for the comparison between benign tumors and ovarian cancer stage III-IV (left panel) and I-II (right panel)

\section{Discussion}

We have searched for plasma proteins that could distinguish between patients with the gynecologic cancers $O C$ and EC and benign tumors, using a two-step study design and a scalable technology for measuring protein abundance. The high degree of multiplexing of PEA panels enabled us to screen 441 unique proteins in search of suitable biomarker candidates. The ability to scale the PEA technology was then used to design two focused multiplex panels for the proteins selected in the discovery step. The abundance estimates for the proteins measured both in discovery step and the replication step showed high correlation and similar precision, testifying to that the PEA technology is scalable without compromising the performance for detection of individual proteins. In fact, by using a smaller Integrated Fluidic Circuit for the analysis, we were able to combine PEA assays for proteins with a greater difference in abundance than is possible using the 92-protein Integrated Fluidic Circuits.

\section{Proteins identified}

Among the proteins we identified as biomarker candidates for OC some have been discussed previously [5], such as Mucin-16 (CA125) and Major epididymisspecific protein E4 (HE4), Midkine (MK) [16, 17], Kallikrein-11 (hK11) [18], Folate receptor alpha (FR) [19, 20] and Prostasin (PRSS8) [21, 22]. Boylan et al. [5] also using PEA technology further reported an association of OC with Interleukin-6 (IL-6) [23-25], Kallikrein-6 (KLK6) [26], Furin (FUR) [27], Chemokine (C-X-C motif) ligand 13 (CXCL13) and Tumor necrosis factor ligand superfamily member 14 (TNFSF14), but none of these proteins were among our top candidates. A number of the proteins we selected for the replication step were not studied by Boylan et al. [5] such as Interleukin-8 (IL-8), Nectin-4 (PVRL4), Interleukin-17C (IL17C), Poly (ADPribose) polymerase-1 (PARP-1), Superoxide dismutase (Mn), mitochondrial (SOD2) and Protein S100-A12 (ENRAGE). Several of these have previously been noted in connection to OC. The level of Interleukin- 8 has been proposed as a diagnostic and prognostic biomarker for OC [28-30]. Nectin-4 is overexpressed in epithelial cancers including $\mathrm{OC}$ and has been proposed as a therapeutic target [31]. Interleukin-17C has been shown to be tumor-promoting in OC cell models [32]. Poly (ADPribose) polymerase 1 is overexpressed in $\mathrm{OC}$ and may enhance angiogenesis by upregulating Vascular endothelial growth factor A (VEGF-A) [33]. Genetic variation in Neurotrophic tyrosine receptor kinase 3 (NTRK3) has been associated with prognosis of $\mathrm{OC}$ and suggested to predict platinum resistance in OC patients [34]. Superoxide dismutase $(\mathrm{Mn})$, mitochondrial, is highly expressed in $\mathrm{OC}$ and has been shown to increase tumor development and metastatic spread [35].

Among the nine proteins (Prostasin (PRSS8), Midkine (Mk), Major epididymis-specific protein E4 (HE4), Adenomedulin (ADM), Matrilysin (MMP-7), Interleukin-1 receptor-like 1 (ST2), Vascular endothelial growth factor A (VEGF-A), Interleukin-6 (IL-6), Hepatocyte growth factor receptor (HGF)) associated with EC in the replication step, several have been discussed in relation to EC. Midkine has been proposed as a serum biomarker 
for high-risk EC patients, and preoperative serum levels have been shown to correlate with lymph node metastasis [36]. Adrenomedullin expression is upregulated in post-menopausal endometria, and is increased during progression from benign endometrium to type- 1 adenocarcinoma [37, 38]. Fatty acid-binding protein (FABP4) has been proposed as a diagnostic biomarker for EC [39, $40]$ and showed a significant association in our discovery step analysis, but not in the replication step.

\section{Preoperative diagnostic}

Our protein panel has a sensitivity $=0.83$ and specificity $=0.87$ to distinguish between benign tumors and $\mathrm{OC}$ stage I-IV. The specificity of our protein panel is somewhat lower than the 0.91 of Overa ${ }^{\circledR}$, while the sensitivity is higher than the 0.69 reported for Overa ${ }^{\circledR}$ [4]. Focusing on OC stage III-IV we have a sensitivity $=0.88$ and specificity $=0.92$, which is significantly higher than using only CA125 and HE4.

A test for triaging women with adnexal ovarian mass should have better performance than TVU. A recent study showed that TVU in the hands of specially trained gynecologic sonographers can achieve an $\mathrm{AUC}=0.92$ [41]. However, the performance of ordinary gynecologists is generally lower. For instance, among women with a TVU indication of adnexal ovarian mass that are diagnosed by surgical sampling, 58\% have been reported to have benign tumors, $30 \%$ have OC stage I-IV and the remaining $15 \%$ borderline tumors [42, 43]. Among the $30 \%$ of women with OC, $15 \%$ have OC stage III-IV. Based on these estimates, clinical diagnosis by surgical sampling has a specificity for OC stage I-IV of 0.30 and for OC III-IV of 0.15. At a minimum sensitivity of 0.96 , used as a threshold for a preoperative diagnostic test, our protein panel can distinguish between benign tumors and OC stage III-IV with a specificity of 0.58 . This indicates that the number of women with OC stage III-IV among those stratified for surgical sampling based on TVU could be increased from $15 \%$ when using TVU to $58 \%$ by using the protein panel. For OC stage I-IV, the protein panel show a specificity of 0.48 , while the specificity of TVU is 0.30 . This correspond to a $50 \%$ increase of the specificity. The combined use of both TVU and the biomarker test is likely to give even higher specificity.

Boylan et al. [5] used the ONC Iv2 panel to search for candidate biomarkers for OC. Several of the proteins found to be associated with OC in their study were also on our list of candidates, such as Major epididymis-specific protein E4, Midkine, Kallikrein-11, Folate receptor alpha. Interleukin-6, and Prostasin. Their list of top proteins had consistently higher AUC values than our estimates (Fig. 7). This may reflect differences in design between the studies. Boylan et al. [5] used a single set of cases and controls for identification of proteins, while we used a two-step analysis with two independent set of clinical materials, and in the replication step we also included OC patients from two different hospitals. Our study thus includes several factors that could introduce variation, such as multiple patient cohorts from both the same and different hospitals, different PEA analysis rounds and using both 92-plex and focused PEA panels, and finally the use of a replication step to verify initial findings. Together these factors are likely to reduce the overall performance characteristics of the assay, while at the same time result in more realistic performance indicators.

We also identified a set of protein biomarkers that can be used to distinguish between benign tumors and EC. Biomarkers have previously been described for EC, and good diagnostic accuracy has been reported for e.g. Major epididymis-specific protein E4 (HE4), Growth/ differentiation factor 15 (GDF-15), C-Jun-amino-terminal kinase-interacting protein 4 (JIP-4), JNK-interacting protein 4 (SPAG9), Chitinase-3-like protein 1 (YKL-40), Interleukin-31 (IL-31) and Interleukin-33 (IL-33) [11]. Further studies are needed to compare the performance of these candidates with the ones identified in the present study.

\section{Population screening}

Our results indicate that the focused protein panel at a specificity of 0.96 has a high sensitivity to distinguish population controls from women with OC stage I-IV and stage III-IV, while lower for stage I-II. To determine the potential of using the protein panel in population screening, further studies are needed of based on samples collected at distinct time-points prior to diagnosis. A recent evaluation of four markers (CA125, HE4, CA72.4, and CA15.3) for OC showed that the performance declined with increasing time between sample collection and time of diagnosis [44]. Serial sampling could enable the use of individual baseline values, and testing women at 3 months rather than 6-12-month intervals using ROCA has been shown to result in better sensitivity and high specificity for detection of early-stage disease [45].

In summary, we have used a two-step strategy to identify plasma proteins that can be used to distinguish benign tumors from $\mathrm{OC}$ or EC and for differential diagnostic procedures of women with suspicious pelvic mass. The biomarker panels could be useful in population screening and to identify women in need of TVU examination at a specialized gynecologic ultrasound unit. 


\section{Additional files}

Additional file 1:Table 1. P-values of individual proteins in the discovery step.

Additional file 2: Table 2. CA125 values in the clinical analyses and the PEA NPX values for some of the benign and ovarian cancer cohorts used in the discovery analysis.

\section{Authors' contributions}

The authors contributed to the different aspects of the study as follows: PI of the study: UG. Study design: UG, KSU. Collection and characterization of clinical materials: KSU, KS, ML. Generation of protein data: ML, EA. Analysis of protein data: MB, SE. Statistical analysis: MB, SE, ML, EA. Writing of the paper: All authors read and approved the final manuscript.

\section{Author details}

1 Department of Immunology, Genetics, and Pathology, Biomedical Center, Science for Life Laboratory (SciLifeLab) Uppsala, Uppsala University, Box 815, 75108 Uppsala, Sweden. ${ }^{2}$ OLINK Proteomics, Uppsala Science Park, 75183 Uppsala, Sweden. ${ }^{3}$ Department of Women's and Children's Health, Uppsala University, Uppsala, Sweden. ${ }^{4}$ Department of Obstetrics and Gynecology, Institute of Clinical Sciences, Sahlgrenska Academy at Gothenburg University, Gothenburg, Sweden.

\section{Acknowledgements}

See Funding.

\section{Availability of data and materials}

The data will be made available upon publication.

\section{Competing interests}

The authors declare that they have no competing interests.

\section{Consent for publication}

Not applicable.

\section{Ethics approval and consent to participate}

The study was approved by the Regional Ethics Committee in Uppsala (Dnr: 2016/145) and Gothenburg (Dnr: 201-15).

\section{Funding}

The study was funded by the Swedish Cancer Foundation, The Swedish Foundation for Strategic Research (SSF), the Swedish Research Council (VR), VINNOVA (SWELIFE) and Olink Proteomics.

\section{Publisher's Note}

Springer Nature remains neutral with regard to jurisdictional claims in published maps and institutional affiliations.

Received: 24 May 2018 Accepted: 22 November 2018

Published online: 01 December 2018

\section{References}

1. Ferley, GLOBOSCAN 2012: Estimated Cancer incidence, mortality and prevlance worldwide 2012. 2012

2. Moore RG, et al. Evaluation of the diagnostic accuracy of the risk of ovarian malignancy algorithm in women with a pelvic mass. Obstet Gynecol. 2011;118(2 Pt 1):280-8.

3. Coleman $\mathrm{RL}$, et al. Validation of a second-generation multivariate index assay for malignancy risk of adnexal masses. Am J Obstet Gynecol. 2016:215(1):82e1-11.

4. Simmons AR, et al. Validation of a biomarker panel and longitudinal biomarker performance for early detection of ovarian cancer. Int J Gynecol Cancer. 2016;26(6):1070-7.

5. Boylan KLM, et al. A multiplex platform for the identification of ovarian cancer biomarkers. Clin Proteomics. 2017;14:34.
6. Lu KH, et al. A 2-stage ovarian cancer screening strategy using the Risk of Ovarian Cancer Algorithm (ROCA) identifies early-stage incident cancers and demonstrates high positive predictive value. Cancer. 2013;119(19):3454-61.

7. Jacobs IJ, et al. Ovarian cancer screening and mortality in the UK Collaborative Trial of Ovarian Cancer Screening (UKCTOCS): a randomised controlled trial. Lancet. 2016:387(10022):945-56.

8. Andreano A, et al. MR diffusion imaging for preoperative staging of myometrial invasion in patients with endometrial cancer: a systematic review and meta-analysis. Eur Radiol. 2014;24(6):1327-38.

9. Salvesen $\mathrm{HB}$, et al. Integrated genomic profiling of endometrial carcinoma associates aggressive tumors with indicators of PI3 kinase activation. Proc Natl Acad Sci USA. 2009;106(12):4834-9.

10. Supernat $A$, et al. A multimarker qPCR platform for the characterisation of endometrial cancer. Oncol Rep. 2014;31(2):1003-13.

11. Rizner TL. Discovery of biomarkers for endometrial cancer: current status and prospects. Expert Rev Mol Diagn. 2016;16:1315-36

12. Assarsson $\mathrm{E}$, et al. Homogenous 96-plex PEA immunoassay exhibiting high sensitivity, specificity, and excellent scalability. PLOS ONE. 2014:9(4):e95192.

13. R Core Team, R: A Language and Environment for Statistical Computing 2014, R Foundation for Statistical Computing.

14. Hong MG, et al. Multidimensional normalization to minimize plate effects of suspension bead array data. J Proteome Res. 2016;15(10):3473-80.

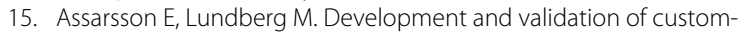
ized PEA biomarker panels with clinical utility, in advancing precision medicine: current and future proteogenomic strategies for biomarker discovery and development. Washington, DC: Science/AAAS; 2017. p. 33-6.

16. Wu X, et al. Midkine as a potential diagnostic marker in epithelial ovarian cancer for cisplatin/paclitaxel combination clinical therapy. Am J Cancer Res. 2015;5(2):629-38.

17. Rice GE, Edgell TA, Autelitano DJ. Evaluation of midkine and anterior gradient 2 in a multimarker panel for the detection of ovarian cancer. J Exp Clin Cancer Res. 2010;29:62.

18. Mclntosh MW, et al. Validation and characterization of human kallikrein 11 as a serum marker for diagnosis of ovarian carcinoma. Clin Cancer Res. 2007:13(15 Pt 1):4422-8.

19. O'Shannessy DJ, et al. Serum folate receptor alpha, mesothelin and megakaryocyte potentiating factor in ovarian cancer: association to disease stage and grade and comparison to CA125 and HE4. J Ovarian Res. 2013:6(1):29.

20. Kurosaki A, et al. Serum folate receptor alpha as a biomarker for ovarian cancer: implications for diagnosis, prognosis and predicting its local tumor expression. Int J Cancer. 2016;138(8):1994-2002.

21. Mok SC, et al. Prostasin, a potential serum marker for ovarian cancer: identification through microarray technology. J Natl Cancer Inst. 2001;93(19):1458-64.

22. Tamir A, et al. The serine protease prostasin (PRSS8) is a potential biomarker for early detection of ovarian cancer. J Ovarian Res. 2016;9:20.

23. Berek JS, et al. Serum interleukin-6 levels correlate with disease status in patients with epithelial ovarian cancer. Am J Obstet Gynecol. 1991:164(4):1038-42 (discussion 1042-3)

24. Tempfer C, et al. Serum evaluation of interleukin 6 in ovarian cancer patients. Gynecol Oncol. 1997:66(1):27-30.

25. Block MS, et al. Plasma immune analytes in patients with epithelial ovarian cancer. Cytokine. 2015;73(1):108-13.

26. Tamir A, et al. Kallikrein family proteases KLK6 and KLK7 are potential early detection and diagnostic biomarkers for serous and papillary serous ovarian cancer subtypes. J Ovarian Res. 2014;7:109.

27. Page RE, et al. Increased expression of the pro-protein convertase furin predicts decreased survival in ovarian cancer. Cell Oncol. 2007;29(4):289-99.

28. Nolen BM, Lokshin AE. Protein biomarkers of ovarian cancer: the forest and the trees. Future Oncol. 2012;8(1):55-71.

29. Sanguinete MMM, et al. Serum IL-6 and IL-8 correlate with prognostic factors in ovarian cancer. Immunol Invest. 2017:46(7):677-88.

30. Hibbs K, et al. Differential gene expression in ovarian carcinoma: identification of potential biomarkers. Am J Pathol. 2004;165(2):397-414. 
31. Boylan $\mathrm{KL}$, et al. The expression of Nectin-4 on the surface of ovarian cancer cells alters their ability to adhere, migrate, aggregate, and proliferate. Oncotarget. 2017;8(6):9717-38.

32. Charles KA, et al. The tumor-promoting actions of TNF-alpha involve TNFR1 and IL-17 in ovarian cancer in mice and humans. J Clin Invest. 2009;119(10):3011-23.

33. Wei $W$, et al. PARP-1 may be involved in angiogenesis in epithelial ovarian cancer. Oncol Lett. 2016;12(6):4561-7.

34. Ge L, et al. Copy number variations of neurotrophic tyrosine receptor kinase 3 (NTRK3) may predict prognosis of ovarian cancer. Medicine (Baltimore). 2017;96(30):e7621.

35. Hemachandra LP, et al. Mitochondrial superoxide dismutase has a protumorigenic role in ovarian clear cell carcinoma. Cancer Res. 2015;75(22):4973-84

36. Tanabe K, et al. Midkine and its clinical significance in endometrial carcinoma. Cancer Sci. 2008;99(6):1125-30.

37. Evans JJ, et al. Adrenomedullin interacts with VEGF in endometrial cancer and has varied modulation in tumours of different grades. Gynecol Oncol. 2012;125(1):214-9.

38. Bozkurt KK, et al. The role of immunohistochemical adrenomedullin and $\mathrm{BCl}-2$ expression in development of type-1 endometrial adenocarcinoma: adrenomedullin expression in endometrium. Pathol Res Pract. 2016;212(5):450-5.
39. Li Z, et al. Prognostic evaluation of epidermal fatty acid-binding protein and calcyphosine, two proteins implicated in endometrial cancer using a proteomic approach. Int J Cancer. 2008;123(10):2377-83.

40. Li Z, et al. Proteomics-based approach identified differentially expressed proteins with potential roles in endometrial carcinoma. Int J Gynecol Cancer. 2010;20(1):9-15.

41. Timmerman $D$, et al. Predicting the risk of malignancy in adnexal masses based on the simple rules from the international ovarian tumor analysis group. Am J Obstet Gynecol. 2016;214(4):424-37.

42. Partheen K, Kristjansdottir B, Sundfeldt K. Evaluation of ovarian cancer biomarkers HE4 and CA-125 in women presenting with a suspicious cystic ovarian mass. J Gynecol Oncol. 2011;22(4):244-52.

43. Kristjansdottir B, Levan K, Partheen K, Sundfeldt K. Diagnostic performance of the biomarkers HE4 and CA125 in type I and type II epithelial ovarian cancer. Gynecol Oncol. 2013;131(1):52-8.

44. Terry $\mathrm{KL}$, et al. A prospective evaluation of early detection biomarkers for ovarian cancer in the European EPIC cohort. Clin Cancer Res. 2016;22(18):4664-75.

45. Skates SJ, et al. Early detection of ovarian cancer using the risk of ovarian cancer algorithm with frequent CA125 testing in women at increased familial risk - combined results from two screening trials. Clin Cancer Res. 2017;23(14):3628-37.
Ready to submit your research? Choose BMC and benefit from:

- fast, convenient online submission

- thorough peer review by experienced researchers in your field

- rapid publication on acceptance

- support for research data, including large and complex data types

- gold Open Access which fosters wider collaboration and increased citations

- maximum visibility for your research: over 100M website views per year

At BMC, research is always in progress.

Learn more biomedcentral.com/submissions 